\title{
Análise do perfil dos consumidores de peixes em Gaspar (SC)
}

\author{
Analysis of the profile of fish consumers in Gaspar (SC) \\ Análisis del perfil de los consumidores de pescado en Gaspar (SC)
}

Recebido: 05/02/2021 | Revisado: 12/02/2021 | Aceito: 17/02/2021 | Publicado: 25/02/2021

\author{
Graciane Regina Pereira \\ ORCID: http://orcid.org/0000-0002-8266-4382 \\ Instituto Federal de Santa Catarina, Brasil \\ E-mail: gracianerp@ifsc.edu.br \\ Marcelo Alberto Elias \\ ORCID: http://orcid.org/0000-0002-1613-376X \\ Instituto Federal do Paraná, Brasil \\ E-mail: marcelo.elias@ifpr.edu.br
}

\begin{abstract}
Resumo
O município de Gaspar (SC) produz peixes de cultivo, colocando o município em sexta posição na produção do estado. Por essa importância econômica buscou-se identificar as preferências dos consumidores de Gaspar em relação à carne de peixe. A metodologia foi embasada em um estudo exploratório-descritivo utilizando instrumento investigativo aplicado a uma amostra da população do município. Os resultados mostraram que o consumidor de peixe de Gaspar é composto na maioria de mulheres, com idade entre 18 a 30 anos, estado civil casado/união estável, com ensino médio completo e renda familiar de 1,1 a 5 salários-mínimos. 88,4\% consomem peixes, sendo que preferência é por peixe de água doce. O consumo de peixes é eventual, cerca de 2 a $5 \mathrm{Kg}$ por família/mês, dentre os motivos para o consumo destacam-se: sabor, alimentação saudável e variação no cardápio. Os peixes são adquiridos principalmente em supermercados e pesque pagues e o consumo se dá nas residências dos consumidores. A espécie preferida é a tilápia, em forma de filé, e são considerados os seguintes aspectos durante a compra: aparência, preço, forma de armazenamento e origem. Dentre os motivos para não consumir aa carne de peixe, o preço tem destaque. Os resultados apontam para a necessidade de um trabalho conjunto entre as organizações que atuam na piscicultura para definir estratégias de formação e divulgação junto à população, envolvendo as escolas, os meios de comunicação, os empresários e produtores, para incentivo do consumo local sustentável.
\end{abstract}

Palavras-chave: Agricultura familiar; Piscicultura; Sustentabilidade.

\begin{abstract}
The municipality of Gaspar (SC) produces farmed fish, placing the municipality in sixth position in the state's production. Because of this economic importance, we sought to identify the preferences of Gaspar consumers in relation to fish meat. The methodology was based on an exploratory-descriptive study using an investigative instrument applied to a sample of the municipality's population. The results showed that the fish consumer of Gaspar is composed mostly of women, aged between 18 and 30 years, married marital status / stable union, with complete high school education and family income of 1.1 to 5 minimum wages. $88.4 \%$ consume fish, with preference for freshwater fish. Fish consumption is occasional, about 2 to $5 \mathrm{~kg}$ per family / month, among the reasons for consumption are: flavor, healthy eating and variation of the menu. The fish are purchased mainly in supermarkets and fish for payment and consumption takes place in consumers' homes. The preferred species is tilapia, in the form of a fillet, and the following aspects are considered during the purchase: appearance, price, form of storage and origin. Among the reasons for not consuming fish meat even more, the price stands out. The results point to the need for joint work between organizations working in fish farming to define training and dissemination strategies among the population, involving schools, the media, entrepreneurs and producers, to encourage sustainable local consumption.
\end{abstract}

Keywords: Family farming; Pisciculture; Sustainability.

\section{Resumen}

El municipio de Gaspar (SC) produce pescado de piscifactoría, colocando al municipio en el sexto puesto de producción del estado. Debido a esta importancia económica, buscamos identificar las preferencias de los consumidores de Gaspar en relación a la carne de pescado. La metodología se basó en un estudio exploratoriodescriptivo utilizando un instrumento de investigación aplicado a una muestra de la población del municipio. Los resultados mostraron que el consumidor de pescado de Gaspar está compuesto mayoritariamente por mujeres, con edades entre 18 y 30 años, estado civil casado / unión estable, con educación secundaria completa e ingresos familiares de 1,1 a 5 salarios mínimos. El 88,4\% consume pescado, con preferencia el pescado de agua dulce. El consumo de pescado es ocasional, alrededor de 2 a $5 \mathrm{~kg}$ por familia / mes, entre los motivos de consumo se 
encuentran: sabor, alimentación saludable y variación del menú. El pescado se compra principalmente en supermercados y el pescado de pago y consumo se realiza en los hogares de los consumidores. La especie preferida es la tilapia, en forma de filete, y durante la compra se consideran los siguientes aspectos: apariencia, precio, forma de almacenamiento y origen. Entre las razones para no consumir aún más la carne de pescado, destaca el precio. Los resultados apuntan a la necesidad de un trabajo conjunto entre las organizaciones que trabajan en la piscicultura para definir estrategias de capacitación y difusión entre la población, involucrando a escuelas, medios de comunicación, empresarios y productores, para fomentar el consumo local sostenible.

Palabras clave: Agricultura familiar; Piscicultura; Sustentabilidad.

\section{Introdução}

O peixe é a proteína animal mais produzida no planeta, em 2017 foram produzidos 172 milhões de toneladas de pescado, desse total 80 milhões são de peixes de cultivo, produção que vem aumentando nos últimos anos (cresceu $60 \%$ em dez anos) e que vai ultrapassar a pesca de captura até 2021 (Peixebr, 2019).

O município de Gaspar contribui com essas projeções, pois aumenta sua produção de peixes cultivados a cada ano. Atualmente é produzido mais de mil toneladas por ano (Pereira, Pires \& Fronteli, 2019), o que coloca o município na sexta colocação de produção de peixe no estado de Santa Catarina (Epagri, 2019). Propiciar e estimular o consumo de peixe local é uma alternativa para a inserção dessa proteína na dieta e apoio direto aos produtores familiares, atendendo aos Objetivos do Desenvolvimento Sustentável, em especial o 2, o qual pretende acabar com a fome, alcançar a segurança alimentar e melhoria da nutrição e promover a agricultura sustentável (Organização das Nações Unidas, 2015).

Conhecer a demanda e preferências do mercado interno para as espécies cultivadas no Brasil é um dos caminhos apontados pela Organização PeixeBr, pois o Brasil está aquém do recomendado de ingestão de proteína de peixe, são consumidos 10kg/hab/ano para 20kg/hab/ano recomendados, e destes $10 \mathrm{~kg}$, apenas $3 \mathrm{~kg}$ são de peixes cultivados (Peixebr, 2020). O trabalho de Mangas et al. (2016) aponta como fatores que dificultam o baixo consumo de peixe no país: baixo investimento na área pesqueira, manejo inadequado dos estoques, degradação das áreas de reprodução, hábitos alimentares da população e o preço elevado do produto. Neste contexto, entender melhor os consumidores é uma etapa importante para alavancar a cadeia produtiva.

O trabalho de Fernandes et al. (2012) fez uma análise bibliográfica e constatou que dentre os 25 trabalhos, 14 sugeriram efeito protetor do consumo de peixes, relacionado às doenças cardiovasculares, depressão, catarata e alguns tipos de câncer. A carne de peixe possui ácidos graxos essenciais, ferro, vitamina B12 e cálcio. Por ser benéfica para a saúde deveria estar mais presente na alimentação dos brasileiros.

Em Gaspar existem produtores amadores e profissionais de peixes, os quais comercializam a produção em mercados locais, como feiras e pesque pagues ou vendem para empresas de beneficiamento, já que só há duas unidades beneficiadoras de peixes no município com inspeção municipal. Por conta do território, rico em corpos de água, há potencial para ampliar a produção de espécies diversas em tanques de cultivo, hoje a espécie mais produzida é a tilápia, de uma forma convencional e intensiva.

A produção convencional é dependente de insumos industrializados como ração e medicamentos, o uso de energia nos equipamentos também é significativo. A busca de alternativas de cultivo com bases agroecológicas precisa ser discutida ao mesmo tempo em que o consumo local é estimulado, essa é uma premissa do Grupo de Pesquisas Pesca e Aquicultura com enfoque agroecológico no Médio Vale do Itajaí e do Núcleo de Pesquisa Aplicada à Pesca e Aquicultura de Gaspar - NUPA.

O objetivo geral do projeto foi identificar as preferências e aspectos que influenciam os consumidores do município de Gaspar em relação à compra de peixe. Como objetivos específicos estabeleceram-se: a) Definir o perfil do consumidor de peixe de água doce de Gaspar; b) Definir estratégias de informação e formação para promoção do consumo de peixe de cultivo 
no município de Gaspar; c) Promover momentos participativos com as partes interessadas relacionados ao consumo da proteína de peixe.

\section{Piscicultura de Gaspar}

No município de Gaspar a piscicultura tem se destacado desde 1989, época da criação da Secretaria de Agricultura do município, quando iniciaram as feiras de peixe vivo, os pesque pagues e a capacitação profissional dos aquicultores, com apoio da Empresa de Pesquisa Agropecuária e Extensão Rural de Santa Catarina - EPAGRI. O município tem um grande potencial para o desenvolvimento da aquicultura em tanques escavados, devido às condições climáticas e geográficas, abundância de água e a proximidade com grandes mercados consumidores. Com uma área de mais 200 hectares de área alagada, a piscicultura vem ocupando destacado lugar na economia local, inclusive com a inserção do peixe na merenda escolar a partir de 2014 (Pereira et al., 2016).

Ao longo das últimas décadas as várias instituições do município vêm desenvolvendo ações para fortalecer e impulsionar a piscicultura local, como a Prefeitura Municipal de Gaspar, o Banco do Brasil, a EPAGRI, a Associação de Aquicultores de Gaspar - AQUIPAR e o próprio NUPA do IFSC. Há uma convergência de esforços das organizações parceiras.

Gaspar conta com 9 pesque pagues que recebem um público anual de mais de 30.000 pessoas, gerando a comercialização de mais de 10 toneladas anuais de peixe por estabelecimento, diversificando as atividades de turismo e lazer e absorvendo a produção local. Contando somente com produtores comerciais, a produção de peixes do município passa das 1000 toneladas anuais, produção repassada para o mercado local, regional e estadual (Informação verbal). Todos esses esforços em torno da piscicultura garantiram em 2019 uma premiação para o Prefeito por conta das ações inovadoras integradas em piscicultura: Prefeito Empreendedor SEBRAE.

\section{Consumo de peixe}

Com a tendência crescente na busca por uma vida mais saudável, a proteína animal advinda de peixes ganhou espaço e vem agradando o paladar da Região Sul, em especial o consumo de peixes de cultivo de água doce. Apesar dos preços não serem os mais atraentes, em comparação ao frango, por exemplo, os consumidores têm colocado, gradativamente, o peixe na mesa.

O conhecimento do comportamento do consumidor é essencial para as empresas ou produtores traçarem suas estratégias e também para tornar mais seguras suas ações no mercado. No contexto do comportamento do consumidor, a tomada de decisão de compra constitui-se relevante, pois a compra é o ato final de um processo que determina a escolha de um produto, serviço ou marca (Dotto, 2012, p. 31).

Entender o comportamento decisório do consumidor é um processo complexo. O ato de consumir é um processo dinâmico sob vários aspectos, como o preço, a qualidade, preferências pessoais, entre outros. Em cada aquisição o consumidor se depara com o produto e elabora todo um processo cognitivo particular para decidir ou não por um produto.

Gade (1980 apud Dotto, 1999) coloca que diante de muitas alternativas possíveis de compra, o indivíduo escolhe e decide sobre qual, na sua percepção, é a mais adequada para satisfazer sua necessidade. Para isso há uma sequência de estágios até a tomada de decisão podendo fazer ou não a compra, isso pode ser em uma fração de segundos como ser fruto de um amadurecimento em um longo período de tempo. 
Segundo Churchill Jr. \& Peter (2000 apud Dutra, Binotto \& Mauad, 2014), durante o processo de compra o consumidor passa por cinco etapas, das quais se denominam: reconhecimento de uma necessidade, busca de informação, avaliação de alternativas, decisão de compra e avaliação da compra. Dependendo do produto ou serviço que o consumidor comprará, ele pode pular ou inverter algumas das etapas

As incertezas do consumidor podem ser reduzidas se houver informação sobre o produto. Segundo Dotto (1999) os consumidores têm muitas opções de compra e os produtores precisam informações sobre o comportamento dos mesmos. Precisam saber o quê, onde, quando e, principalmente, porque eles compram. Com essas informações estratégias que atraiam o consumidor podem ser traçadas, considerando o produto em si, seus atributos; o preço, que é a relação entre o custo calculado pelo produtor para colocação do produto no mercado e a avaliação do consumidor do custo de aquisição (tempo, conveniência, oportunidade e risco); promoção (comunicação), o uso de ferramentas (propaganda, relações públicas, promoções e venda direta) para criar na mente do consumidor uma predisposição favorável em relação ao produto; e a distribuição, como tornar o produto disponível para uso ou consumo, propiciando ao consumidor menor dispêndio de tempo e de recursos.

Existe a produção de peixe de água doce em Gaspar, em especial a tilápia, produção que pode ser ampliada se for conhecido o consumidor e traçado estratégias pode alavancar a produção local, aproximando produtor e consumidor, assegurando assim a segurança alimentar e nutricional.

\section{Metodologia}

A pesquisa está enquadrada na área de Ciências Agrárias, subárea de Recursos Pesqueiros, Piscicultura. Tem características quanti-qualitativas.

Em um primeiro momento o trabalho teve caráter exploratório, se fez aprofundamento bibliográfico sobre o tema, técnicas de pesquisa e outras experiências junto às fontes disponíveis (livros, artigos, sites). Essa fase foi importante para embasar a equipe.

Em um segundo momento se fez a pesquisa descritiva com instrumentos definidos para buscar os dados junto aos consumidores do município de Gaspar. Para Mattar (1996), a pesquisa descritiva descreve características de um grupo; estima a proporção de uma população ou universo que tenha um determinado tipo de comportamento ou característica; verifica a existência de relação entre variáveis. Nesta etapa houve a participação dos consumidores do município de Gaspar, utilizando a aplicação de um questionário estruturado. As questões foram claras e objetivas. Antes da aplicação final o instrumento foi testado e validado a partir de uma amostra do grupo focal. Os aspectos estudados estavam relacionados ao perfil do consumidor: sexo, idade, renda, instrução e demais fatores que influenciam a compra. Ao todo foram 14 questões abertas e fechadas (Apêndice 1).

Para a definição da amostra, considerou-se a população ocupada de Gaspar, que segundo dados de 2017 do IBGE totalizam 27.198 pessoas, os potenciais consumidores pagantes de proteína de peixe. A amostra foi simples, com uma margem de erro menor que $5 \%$ e um coeficiente de confiança de $95 \%$ totalizando 448 pessoas.

A aplicação dos questionários junto aos consumidores ocorreu em dois momentos. Como o início da aplicação coincidiu com o início da pandemia do COVID 19 - março de 2020 optou-se por enviar os questionários via redes sociais (facebook e whatsapp) para contatos maiores de idade, aleatoriamente selecionados que constavam nos seus perfis como moradores de Gaspar. Como essa estratégia não se atingiu o quantitativo estabelecido, em uma segunda etapa, a aplicação foi realizada de forma presencial em supermercados de Gaspar em períodos distintos do dia, abrangendo consumidores diversos que aceitaram responder às questões. A aplicação só foi realizada quando o estado de Santa Catarina saiu do bandeiramento de risco grave de contaminação pelo COVID-19, em setembro de 2020. Para aplicação das entrevistas nos supermercados 
solicitou-se autorização das respectivas chefias. Os questionários foram aplicados em cinco supermercados de cinco bairros diferentes de Gaspar (Figueira, Margem Esquerda, Centro, Sete de Setembro e Santa Terezinha), esses supermercados são frequentados por praticamente toda a população, pois são os maiores da cidade.

Os dados foram transferidos para planilha do Calc, sendo tabulados, categorizados e quantificados, gerando gráficos e quadros, para propiciar a análise dos resultados e subsidiar a etapa posterior de definição das estratégias para incentivo do consumo de peixe no município.

Após a análise dos resultados da pesquisa houve apresentação junto à Associação dos Aquicultores de Gaspar e Secretaria de Agricultura e Aquicultura por meio de uma reunião. Durante a reunião se definiu a estratégia para dar continuidade ao trabalho de construção participativa junto aos principais atores do município.

Em um terceiro momento se elaborou uma pré-proposta de formação e informação para promoção do consumo de peixe de água doce no município de Gaspar. Para essa etapa também se previa uma oficina presencial com utilização de metodologias participativas com apoio de material específico adquirido para esse fim. Como não foi possível, a continuidade se dará em momentos posteriores, sem risco para os participantes.

\section{Resultados e Discussão}

\subsection{Perfil socioeconômico dos consumidores de peixes de Gaspar}

Para entender quem é esse consumidor que se dirige às compras foram elaboradas questões relacionadas ao indivíduo e sua família.

Dos entrevistados, 244 eram mulheres e 204 eram homens, um público um pouco maior de mulheres vão às compras. Com relação à idade dos consumidores, a maioria é jovem, na fase economicamente ativa, com idade entre 18 e 60 anos (Figura 1), portanto potenciais consumidores.

Figura 1 - Faixa etária dos entrevistados (\%).

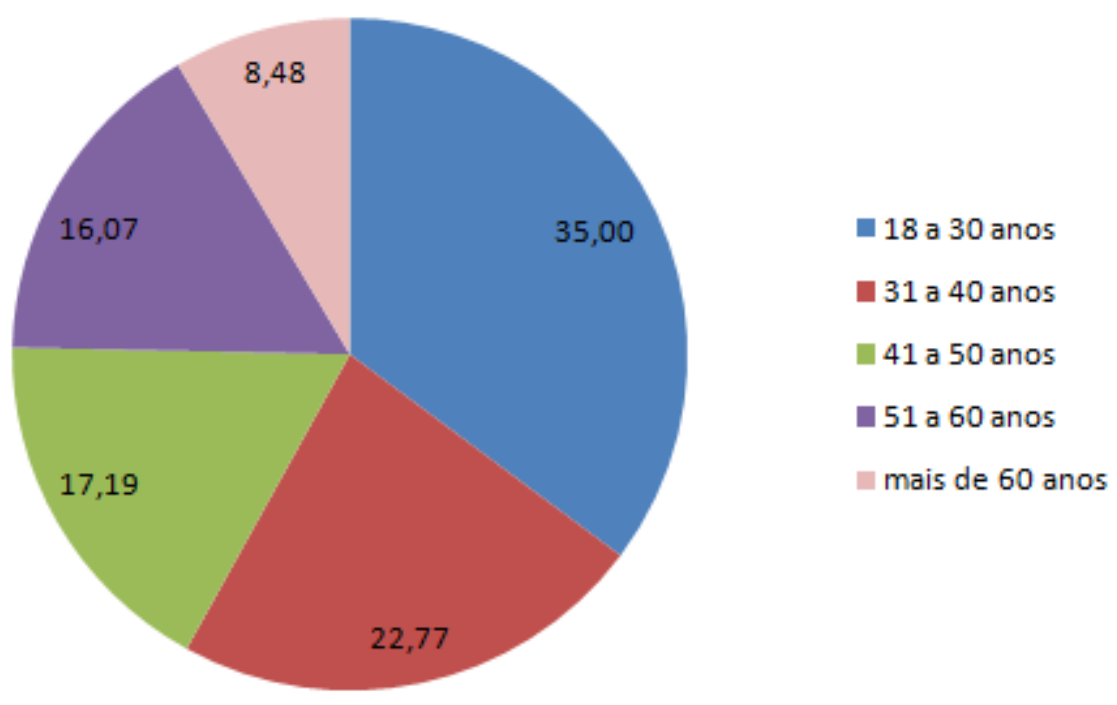

Fonte: Autores. 
O estado civil da maioria dos entrevistados é casado ou em união estável (52,9\%), seguido dos solteiros (32,59\%), divorciados $(8,48 \%)$, viúvos $(3,35 \%)$ e separados $(2,68 \%)$.

A renda familiar dos entrevistados pode ser visualizada na figura 2. Percebe-se que a maioria tem renda de 1,1 a 5 salários mínimos.

Figura 2 - Renda familiar dos entrevistados (\%).

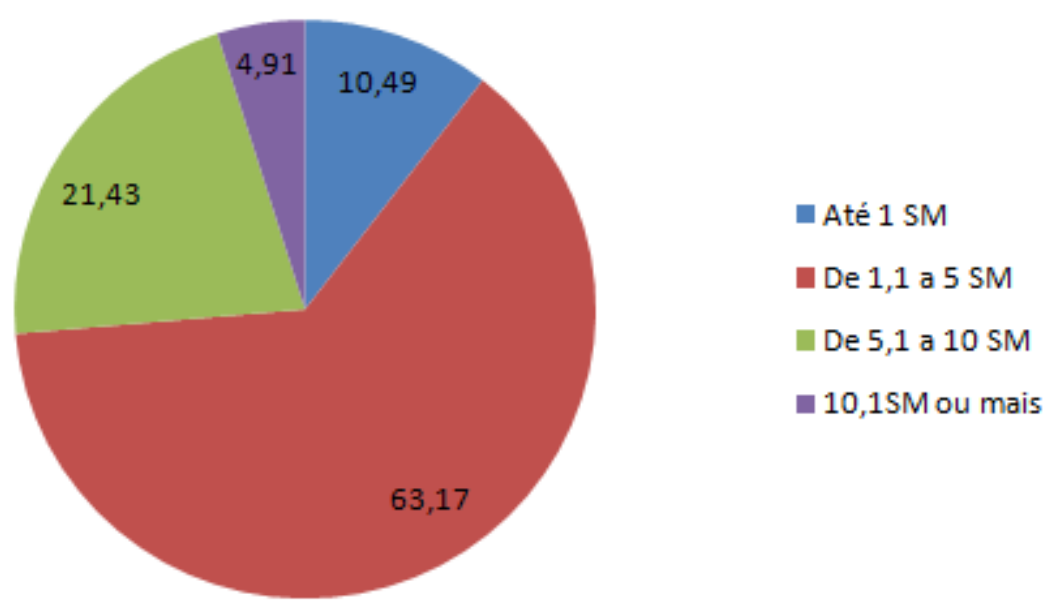

Fonte: Autores.

A escolaridade levantada junto aos entrevistados (quadro 1) mostra que o percentual maior está com os que possuem o ensino médio completo (educação básica) (27\%) e graduação completa (20,4\%).

Quadro 1 - Escolaridade dos entrevistados.

\begin{tabular}{|l|l|}
\hline Escolaridade & $\%$ \\
\hline Analfabeto & - \\
\hline Ensino fundamental incompleto & 8 \\
\hline Ensino fundamental completo & 8 \\
\hline Ensino médio incompleto & 9,17 \\
\hline Ensino médio completo & 27 \\
\hline Graduação completa & 20,4 \\
\hline Graduação incompleta & 15,4 \\
\hline Pós-graduação incompleta & 1,8 \\
\hline Pós-graduação completa & 10 \\
\hline
\end{tabular}

Fonte: Autores. 
Com relação à naturalidade, 56,2\% são gasparenses, 24,1\% são de outras cidades de Santa Catarina e 19,1\% são de outros estados ou países, indicando que a maioria é composta de consumidores da cidade. Dos entrevistados $86,38 \%$ residem em zona urbana e 13,61 em zona rural. Dados similares aos de IBGE: 81,27\% constituem a população urbana e 18,72 a população rural (instituto brasileiro de geografia e estatística, 2010).

O número de pessoas que compõem as famílias das pessoas amostradas é praticamente dividido em 2,3 e 4 pessoas (figura 3). São famílias pequenas, corroborando os dados do IBGE, em 2008 o número de pessoas por família era 3,3 (Instituto brasileiro de geografia e estatística, 2008). Considerar também pessoas que moram sozinhas, um mercado que cresce, segundo pesquisa do Serviço de Proteção ao Crédito o mercado precisa atender melhor a este público, oferecendo opções de consumo que se ajustem às necessidades do dia a dia, pois constatou-se que 44,4\% têm dificuldade em não deixar coisas estragarem na geladeira ou na despensa, ao passo em que 41,6\% sentem dificuldade em encontrar produtos que tenham a quantidade adequada para quem mora sozinho (Serviço de proteção ao consumidor, 2017). Considerando isso, porções menores de peixes nas embalagens, ou porções menores dos pratos pré-preparados precisam ser disponibilizadas nos postos de venda.

Figura 3 - Número de pessoas que formam as famílias dos entrevistados (\%).

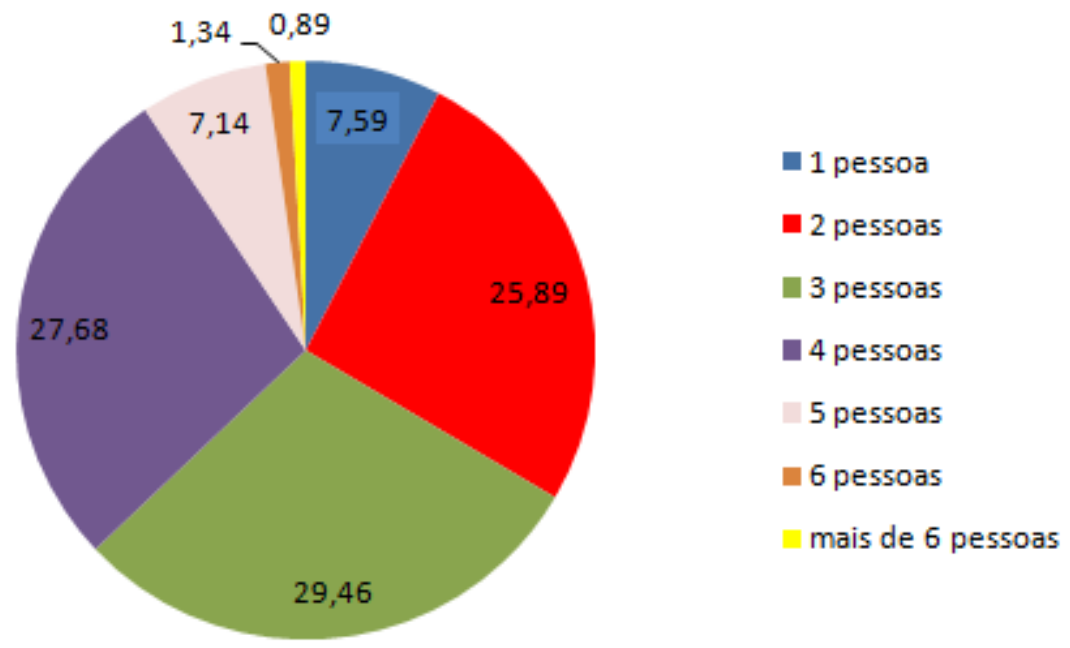

Fonte: Autores.

\subsection{Preferências no consumo de peixes}

Quando perguntados sobre consumo de peixes, 88,4\% dos entrevistados afirmam que consomem peixes e $11,6 \%$ que não consomem. O trabalho de Barcelos et al. (2016) apresenta um percentual mais baixo de pessoas que não consomem peixes: $3 \%$.

Dos que disseram não consumir peixes foram citados os motivos listados no quadro 2. Percebe-se que alguns dos motivos são fatores que podem ser gerenciados na promoção do consumo, como por exemplo, o preço. O motivo 'ter espinhas', mostra a desinformação dos consumidores sobre os vários tipos de cortes feitos que eliminam as espinhas, como por exemplo, os filés de tilápia ou outros pré-preparados. Outros motivos apontados, os quais podem ser gerenciados, são a falta de hábito e o fato de não saber preparar. Os motivos inerentes aos aspectos sensoriais de cada indivíduo são mais difíceis 
de mudar, por isso a importância do consumo na infância, em especial na merenda escolar, criando experiências de degustação.

Quadro 2 - Motivos do não consumo de peixe.

\begin{tabular}{|l|l|}
\hline Motivos & $\%$ \\
\hline Por ser caro & 32,72 \\
\hline Ter espinhas & 23,63 \\
\hline Não gostar do sabor & 16,36 \\
\hline Não comer carne & 12,72 \\
\hline Não ter o hábito & 7,27 \\
\hline Não gostar do cheiro & 3,63 \\
\hline Não fazer bem & 1,81 \\
\hline Não saber preparar & 1,81 \\
\hline
\end{tabular}

Fonte: Autores.

Nas análises que seguem, foram entrevistados apenas os consumidores que afirmaram consumir peixe, os demais responderam apenas a pergunta final sobre o conhecimento da piscicultura no município de Gaspar.

A próxima questão buscava saber qual a preferência dos consumidores com relação ao ambiente de criação dos peixes: água doce ou salgada. A pesquisa mostrou que a preferência dos consumidores de Gaspar é pelo peixe criado na água doce: $64 \%$, e 20,6\% preferem os peixes de água salgada, enquanto o restante disse gostar de ambos (15,3\%). Somando os que gostam dos peixes de água doce com os que gostam de ambos, podemos afirmar que peixes de água doce têm uma excelente aceitação $(79,3 \%)$.

Sobre a frequência de consumo do peixe, $58,8 \%$ dos entrevistados que consomem peixe afirmaram consumir eventualmente, $35,1 \%$ consomem de 1 a 2 vezes por semana e apenas $6 \%$ consomem de 3 a 4 vezes por semana. Não houve indicação de um consumo semanal mais frequente ou diário. O trabalho de Mangas et al. (2016) em Belém (PA) mostra um consumo mais frequente, são $44,75 \%$ que consomem peixe de 1 a 2 vezes por semana. Sabe-se que o consumo de carne vermelha e frango é culturalmente mais comum na região de Gaspar, esse baixo consumo poderia ser investigado comparando às demais carnes consumidas.

Buscando entender qual quantidade de peixe entra no cardápio mensal das famílias, questionou-se quantos quilos são consumidos por mês. As respostas foram bastante variadas e categorizou-se por quantidades de consumo, conforme quadro 3 . 
Quadro 3 - Consumo familiar mensal de peixes pelos entrevistados.

\begin{tabular}{|l|l|}
\hline Quantidade de peixe consumida por mês & $\%$ \\
\hline $0,2 \mathrm{Kg}$ a $1 \mathrm{Kg}$ & 26,76 \\
\hline $2 \mathrm{Kg}$ a $5 \mathrm{Kg}$ & 56,22 \\
\hline $6 \mathrm{Kg}$ a $10 \mathrm{Kg}$ & 9,46 \\
\hline Mais de $10 \mathrm{Kg}$ & 3,51 \\
\hline Não sabe informar & 4 \\
\hline
\end{tabular}

Fonte: Autores.

Em uma das questões com múltipla escolha, os entrevistados podiam apontar os motivos pelos quais consomem peixes, o resultado das respostas é apresentado no quadro 4.

Quadro 4 - Motivos para consumir peixes.

\begin{tabular}{|l|l|}
\hline Motivos para consumir peixe & $\%$ \\
\hline Pelo sabor & 37,52 \\
\hline Para ter uma alimentação saudável & 26,29 \\
\hline Para variar o cardápio & 23,93 \\
\hline Pelas tradições religiosas & 4,43 \\
\hline Porque é carne branca & 3,69 \\
\hline Por recomendação médica & 3,25 \\
\hline Pelo preço & 0,8 \\
\hline
\end{tabular}

Fonte: Autores.

A relação do consumo de peixe com saúde teve expressivo percentual $(26,29 \%)$, os peixes contêm proteína de alta qualidade e vitaminas e minerais, como as carnes vermelhas e as de aves. Por conter alta proporção de gorduras saudáveis (gorduras insaturadas) os peixes são excelentes para compor o cardápio das pessoas (BRASIL, 2014). Essa relação de preferência pelo peixe por ser saudável e pelo sabor, também foi citada no trabalho de Mangas et al. (2016) com consumidores do município de Belém (PA) e também no trabalho de Nunes (2018) em uma amostra sul-matogrossense.

A associação da carne de peixe com motivos religiosos auxilia no consumo de peixes, o trabalho de Santos e Zamberlan (2017) aponta que a venda do pescado no Brasil é alavancada no período entre o carnaval e a Páscoa, além de outras datas como dia das mães, natal e ano novo.

Questionou-se sobre o local de consumo de peixes. A figura 4 mostra que a maioria consome peixe em suas residências, ou seja, compram e preparam seus pratos (55,3\%). Essa opção também foi preferida no trabalho de Mangas et al. (2016) por $86,1 \%$ dos consumidores. Porém o consumo também é realizado nos restaurantes ou bares $(23,15 \%)$ e pesque pagues $(13,12 \%)$. O município de Gaspar tem se destacado no turismo pelos parques aquáticos e pesque pagues, locais onde são servidos pratos à base de peixe. O município realiza o Festival da Tilápia, por isso a opção 'eventos' foi colocada como alternativa, porém o percentual foi baixo $(7,81 \%)$, indicando que o evento precisa ser mais divulgado para atrair a população. 
Figura 4 - Locais de consumo do peixe (\%).

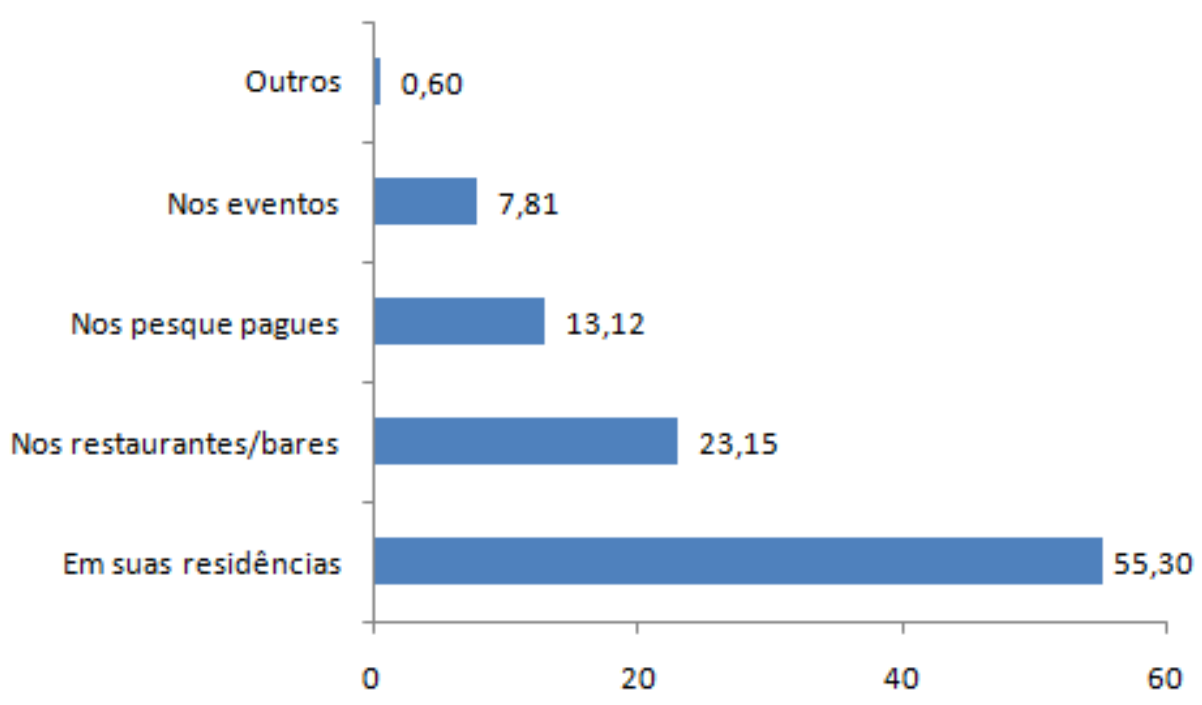

Fonte: Autores.

Na figura 5 observa-se que os locais de compra dos peixes são diversificados. Destaca-se o supermercado com 31,76\%. Manga et al. (2016) aponta que o supermercado é um espaço mais prático, pois permite diversas formas de pagamento, horários bem flexíveis, segurança, produtos sempre disponíveis e armazenados corretamente. Porém, como o município têm vários pesque pagues e boa parte dos consumidores adquirem direto nesses estabelecimentos (28,77\%), isso mostra a confiança dos consumidores com o trabalho dos piscicultores. Essa confiança também é demonstrada pelos que compram direto dos produtores, profissionais e amadores de Gaspar (10,7\%) ou pescam seu próprio peixe em locais variados $(11,32 \%)$. As feiras municipais também são espaços que vendem peixes (9\%), como também as esporádicas feiras de peixes vivos $(3,45 \%)$, em especial nos dias religiosos. Há os que prefiram as peixarias $(2,8 \%)$ ou outros meios de compra $(2,2 \%)$ como vendedores ou carros que passam nas ruas. Os supermercados também foram os mais apontados no trabalho de Santos e Zamberlan (2017). 
Figura 5 - Locais de compra de peixe (\%).

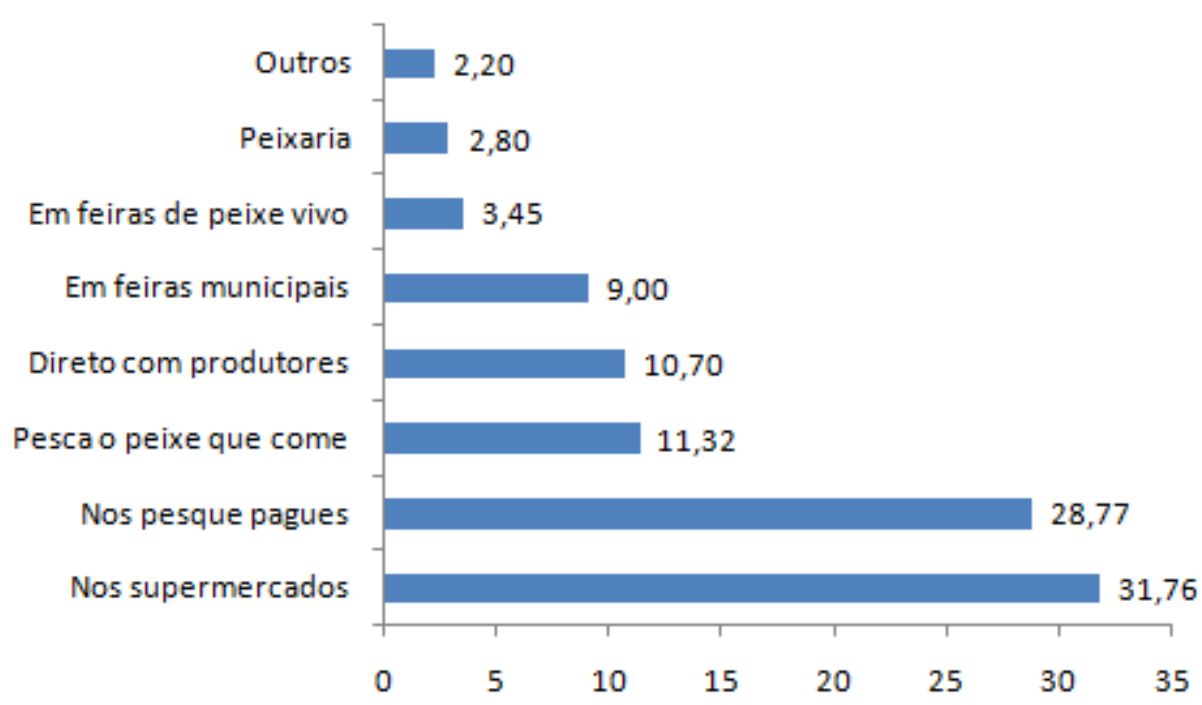

Fonte: Autores.

A carne de peixe é vendida de várias formas, que vai do peixe vivo até um prato pronto com a carne de peixe. A preferência do consumidor com relação a isso foi uma das questões. Praticamente a metade dos entrevistados prefere o filé de peixe congelado (49,5\%). O peixe eviscerado ou limpo inteiro é preferido por $25 \%$ dos entrevistados e $20 \%$ prefere peixes em postas. A carne pré preparada ou os pratos prontos de peixes (lasanha, almôndegas, escondidinho, etc.) é preferido por $5,3 \%$ dos entrevistados.

$\mathrm{Na}$ busca pela praticidade de preparo dos alimentos, os peixes que forem processados antes da venda além de agregar valor podem agradar ainda mais os consumidores, no passado os peixes eram praticamente vendidos apenas eviscerados ou inteiros. A inserção de unidades de processamento em Gaspar e na região permitiu a viabilidade dos peixes filetados e em postas, o que já é preferido por 70\% dos entrevistados. O trabalho de Bombardelli, Syperreck e Sanches (2005) sugere que produtos mais elaborados ou pré-prontos como salgados, defumados, enlatados, embutidos, reestruturados e fermentados precisam ser estudados, gerando mais renda aos produtores. Os autores citam também o aproveitamento dos resíduos, tanto para a produção de farinha, silagem e óleo, quanto para o curtimento das peles, obtendo ganhos econômicos e ambientais.

O momento da compra é marcado por vários fatores individuais. Cada consumidor atenta para algum aspecto o qual é inerente às suas percepções e preferências. Os consumidores de Gaspar consideram vários aspectos na aquisição do peixe. O resultado é apresentado na figura 6 . 
Figura 6 - Aspectos avaliados no momento da compra pelos consumidores (\%).

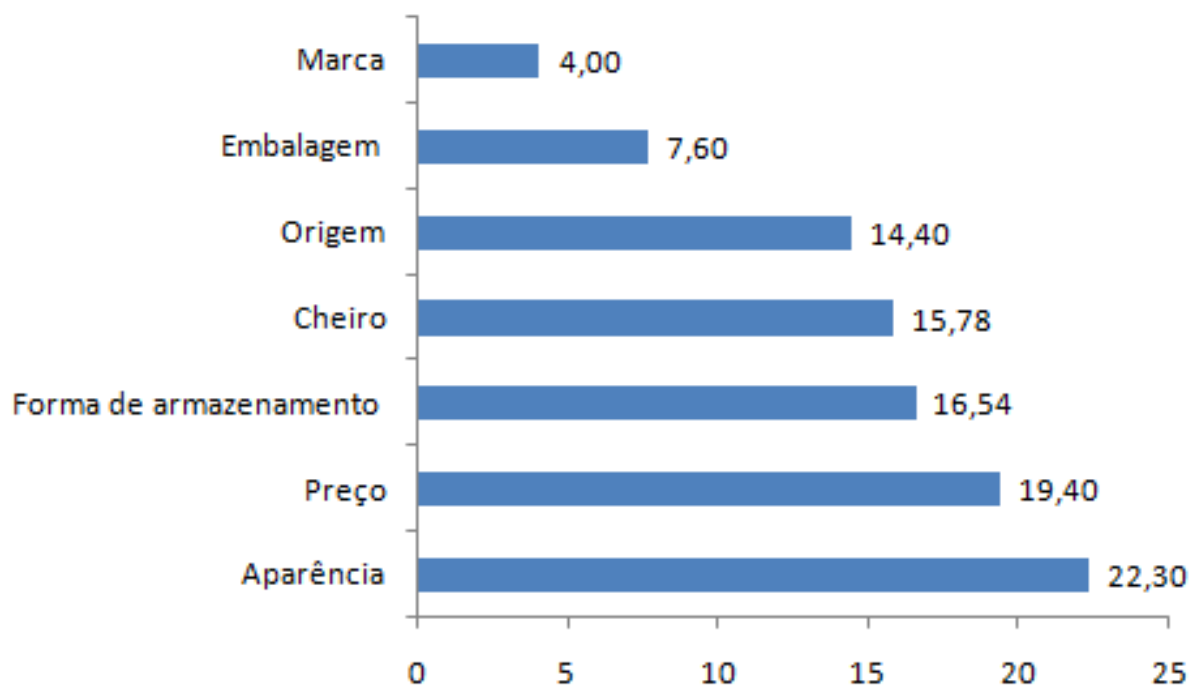

Fonte: Autores.

Buscando subsídios para futuros trabalhos de divulgação e promoção do consumo de peixe, se questionou os motivos pelos quais as pessoas não consomem ainda mais peixe no seu cotidiano. 35,3\% dos apontamentos indicam o alto preço dos peixes; $29,7 \%$ apontam a falta de hábito de consumir mais carne de peixe; a preferência por outras carnes, além do peixe, foi apontada 14,3\%; outros motivos apontados para não consumir mais peixe foram: a presença de espinhas nos peixes (7,5\%), dificuldade de encontrar peixes para comprar (6,3\%), dificuldade em preparar o peixe (4,5\%), dificuldade de armazenar o peixe $(1,3 \%)$ e a incerteza da origem, possibilidade de serem produzidos em águas poluídas (1\%).

O preço do peixe cultivado em tanques é proporcional aos gastos despendidos na sua criação. Os produtores têm gastos altos com a ração, adquirida de empresas especializadas adaptadas para cada fase de desenvolvimento dos peixes. A cadeia do pescado ainda tem as empresas de processamento, distribuição e o comércio final. O preço alto do peixe também foi apontado no trabalho de Santos e Zamberlan (2017) no qual é colocado que dependendo do peixe o valor pode ser dez vezes maior que a carne suína, por quilo.

Em Gaspar são produzidas diversas espécies de peixes de água doce em tanques escavados. Para saber a preferência pela espécie cultivada em água doce questionou-se os participantes. O resultado é apresentado na figura 7. A tilápia representa a preferência de mais da metade dos consumidores, confirmando sua ascensão na produção, não só em Gaspar, mas no Brasil. 
Figura 7 - Espécies de peixes de água doce preferidas pelos consumidores de Gaspar (\%).

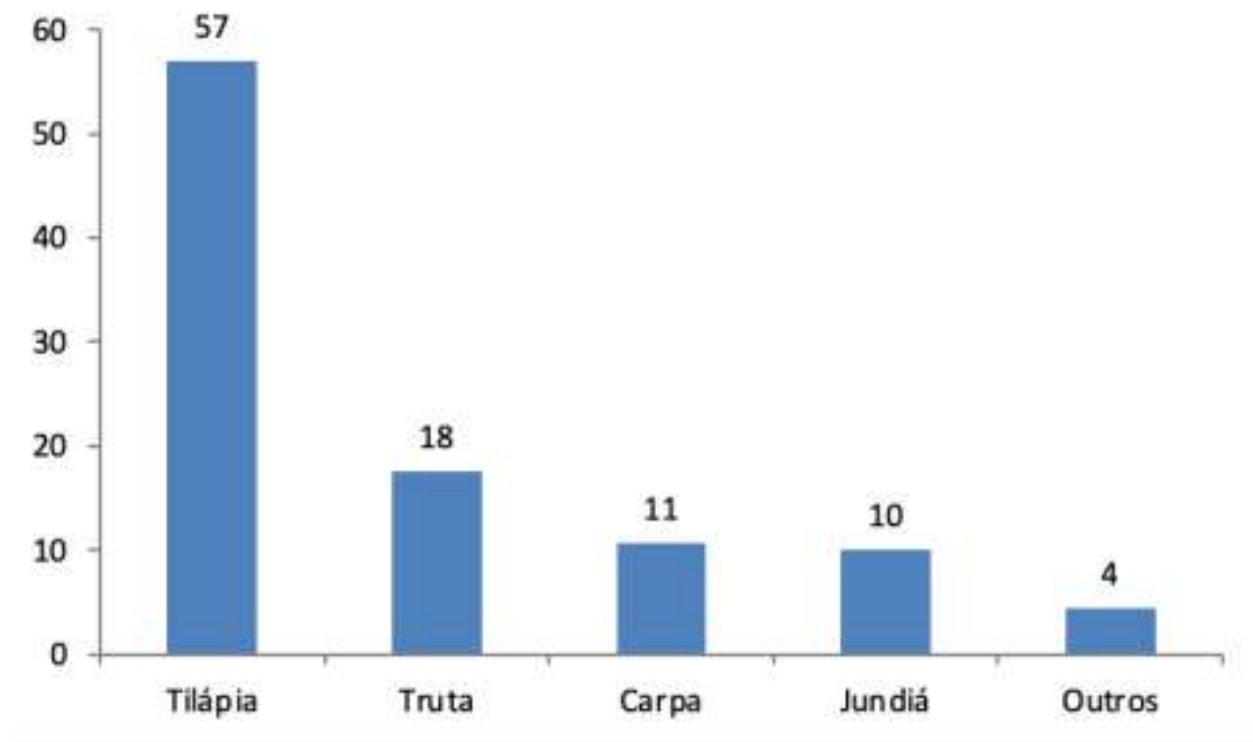

Fonte: Autores.

Alguns participantes (3\% no total) apontaram que os peixes de água doce podem ter gosto de "barro", "de terra", "de lodo". O trabalho de Souza, Mathies e Fioravanzo (2012) afirma que a percepção é uma sensação individual, mas que o gosto de terra molhada e mofo frequentemente relatado pelas pessoas que consomem peixes cultivados em água doce está relacionada à presença de geosmina e do 2 metilisoborneol no ambiente aquático, substâncias produzidas por cianobactérias e actinomicetos e absorvidos por difusão pelos tecidos dos peixes.

\subsection{Conhecimento sobre a piscicultura de Gaspar}

A última questão respondida por todos os participantes foi sobre o conhecimento da piscicultura do município de Gaspar. A questão era aberta e mostrou que 50,2\% dos participantes não conhecem a atividade de piscicultura de Gaspar, ao responder "nada", "quase nada" ou "não conheço". O restante demonstrou conhecer alguma atividade desenvolvida no município, houve respostas associadas à produção de peixes (30\%), como: "existem produtores de tilápia e truta", "tem uma produção organizada", "Uns dos maiores produtores de SC", entre outras respostas similares. Citações ligadas aos pesque pagues - 16,7\% das respostas, também foram importantes indicativos do conhecimento da atividade no município: "Tem pesque pague", "Temos muitos pesque pagues em nossa região de ótima qualidade", entre outras. E também houve respostas citando a AQUIPAR (2,4\%). Se metade dos entrevistados não sabe das atividades de piscicultura, há que se trabalhar na divulgação.

\subsection{Proposta para incentivo do consumo de carne de peixe em Gaspar}

Os resultados apresentados apontam para a necessidade de ações para incentivar o consumo da carne de peixe no município de Gaspar. Entende-se que as várias instituições relacionadas à piscicultura podem contribuir na construção de uma campanha educativa e de divulgação sobre a atividade realizada no município, promovendo a valorização dos produtores e o incentivo ao consumo local de peixes.

Essa construção participativa, a partir dos resultados, estava prevista no planejamento inicial do projeto, porém por conta da pandemia, essa atividade foi postergada. Sugere-se que a campanha contenha ações de sensibilização junto às crianças 
e jovens do município de Gaspar; ações de cunho político-administrativo pelos órgãos públicos, AQUIPAR e empresários; e ações de divulgação pelas mídias junto à população em geral.

Para lograr êxito a rede de atores sociais locais precisa se articular, planejando, executando e avaliando toda a campanha. Abaixo a proposição inicial da rede, a partir do contexto do município de Gaspar com os atores principais identificados.

Figura 8 - Principais atores sociais relacionados com o incentivo ao consumo de peixe.

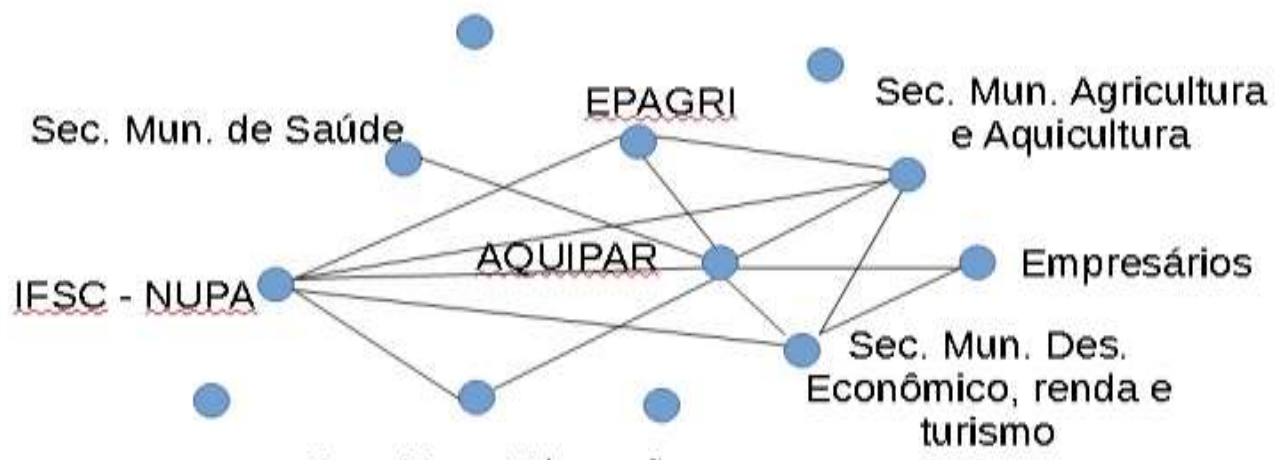

Sec. Mun. Educação

Fonte: Autores.

O espaço escolar - da educação infantil à pós-graduação, apresenta-se como um potencial local para construção e consolidação dessas ações. Para Lima et al. (2013) a organização didática pedagógica pode envolver desde a formação de professores até a capacitação dos servidores da escola envolvidos no preparo da alimentação escolar. Contudo, em especial na formação docente, devem fazer parte dos seus objetivos temas como: saúde e segurança alimentar, saúde na escola e sustentabilidade. Em todos os temas fazer relação com os benefícios do peixe como alimentação. Este processo formativo deve ainda ser organizado de maneira a dar um suporte conceitual baseado em bons referenciais teóricos, além de apresentar sugestões didático metodológicas tais como, planos de aula, sequências didáticas, projetos de ensino, feira de ciências ou mostras científicas sempre norteadas pela temática "peixe como alimentação saudável (Lima et al., 2013).

No âmbito municipal, por conta da proximidade dos órgãos públicos com a sociedade, há uma maior facilidade em estabelecer parcerias e ações locais. Considerando isso, existe também um potencial dessa parceria alavancar a produção e o consumo do peixe no município. Por exemplo, com o apoio técnico, com as compras públicas para a merenda, incentivo ao turismo local, engajamento dos empresários, entre outras ações que podem ser pactuadas entre os atores.

As mídias têm especial importância em campanhas como essa, pois são acessadas por praticamente toda a população. Para isso, materiais específicos para tipo de mídia precisam ser construídos e divulgados, preferencialmente nas mídias digitais, as quais atingem um público bem diversificado.

\section{Considerações finais}

Os dados levantados permitiram definir o perfil socioeconômico do consumidor de Gaspar: a maioria é formada por mulheres (54\%), com idade entre 18 e 30 anos (35\%), o estado civil preponderante é casado/união estável (52,9\%), com ensino médio completo (27\%) e renda familiar de 1,1 a 5 SM (63,17\%), e sua família é composta por 3 pessoas (29,5\%). 
Com relação ao consumo de peixe, os dados mostram que 88,4\% da amostra consomem peixes, sendo que a preferência é por peixe de água doce (64\%). O peixe é consumido eventualmente, cerca de 2 a $5 \mathrm{Kg}$ por família/mês, quantidade que fica aquém do recomendado, e entre os motivos citados para não consumir mais peixe o preço tem destaque $(35,3 \%)$. A busca por estratégias para diminuir custos da produção deve ser considerada pelos produtores.

Dentre os motivos para o consumo destacam-se o sabor, a alimentação saudável e a variação do cardápio. Os peixes são adquiridos principalmente em supermercados $(31,76 \%)$ e pesque-pagues $(28,77 \%)$ e o consumo se dá nas residências dos consumidores $(55,3 \%)$.

A espécie de peixe preferida é a tilápia (57\%), sendo o filé de peixe o escolhido $(49,5 \%)$ na hora da compra. Os fatores considerados pelos consumidores são: a aparência (22,3\%), preço (19,4\%), forma de armazenamento (16,54\%) e a origem $(14,4 \%)$. Sobre o conhecimento da atividade de piscicultura de Gaspar, praticamente metade da amostra conhece a atividade.

A pesquisa buscou preencher a lacuna sobre o comportamento do gasparense com relação ao consumo de peixe, fornecendo dados para etapas posteriores de estratégias de formação e divulgação, como também municiar os produtores sobre as preferências da população.

As ações desenvolvidas pelo NUPA nos últimos anos mostraram como são eficazes as ações desenvolvidas de forma integrada e articulada entre as várias organizações envolvendo a piscicultura. Os próximos passos serão realizados de forma participativa com os atores do município.

\section{Referências}

Barcelos, S. C.; Sá, D. M. T.; Silva, E. F., Castro, A. A. (2016). Perfil dos consumidores de pescados da cidade de Sobral CE. SEMIC. IFCE. http://prpi.ifce.edu.br/nl/_lib/file/doc794-Trabalho/Samuel\%20SEMIC-Final.pdf.

Bombardelli, R. A., Syperreck, M. A., Sanches, E. A. (2005). Situação atual e perspectivas para o consumo, processamento e agregação de valor ao pescado. Arq. ciên. vet. zool.UNIPAR, 8(2), 181-195. https://core.ac.uk/download/pdf/235582163.pdf.

Brasil. Ministério da Saúde. Secretaria de Atenção à Saúde. Departamento de Atenção Básica. Guia alimentar para a população brasileira.Ministério da Saúde, Secretaria de Atenção à Saúde, Departamento de Atenção Básica. - 2. ed. Brasília: Ministério da Saúde, 2014. 156 p.

Dotto, D. M. R. Mercado da carne de peixe de água doce em Santa Cruz do Sul/RS/Brasil: uma análise do comportamento do consumidor. 1999. Dissertação de Mestrado. Curso de Desenvolvimento Regional. Santa Cruz do Sul UNISC.128 f.

Dutra, F. M., Binotto, E., Mauad, J. R. C. (2014). Uma análise do comportamento do consumidor de peixe em Dourados/MS. Sociedade e desenvolvimento rural online $-8(2)$.

EPAGRI. Síntese Anual da Agricultura de Santa Catarina. Florianópolis: EPAGRI/CEPA, 2019.

Instituto Brasileiro De Geografia E Estatística.Tamanho médio da família por situação do domicílio. 2008. https://sidra.ibge.gov.br/tabela/759\#resultado.

Instituto Brasileiro De Geografia $\quad$ E $\quad$ Estatística.Cidades: $\quad$ Gaspar. 2010. https://cidades.ibge.gov.br/brasil/sc/gaspar/pesquisa/23/25207?indicador=25191.

Instituto Brasileiro De Geografia E Estatística. Gaspar: Trabalho e rendimento. 2017. https://cidades.ibge.gov.br/brasil/sc/gaspar/panorama.

Fernandes, Ana Carolina et al. (2012). Benefícios e riscos do consumo de peixes para a saúde humana.Rev. Nutr.[online]. 25(2), 283-295.

Lima, C. F. M.,Pinto, M. L., Kato, H. C. De A., Pires, C. R. F. (2018). Relato de experiência de educação nutricional para o incentivo do consumo do pescado entre escolares do ensino fundamental em Palmas, Tocantins. Em Extensão. 16(1), $140-149$. 
Mangas, F. P., Rebello, F. K., Santos, M. A. S., Martins, C. M. (2016). Caracterização do perfil dos consumidores de peixe no município de Belém, estado do Pará, Brasil. Revista em Agronegócio e Meio Ambiente, 9(4), 839-857.

Mattar, F.N. (1996). Pesquisa de marketing. São Paulo, Atlas.

Nunes, L. P. (2018). Consumo de peixes: uma aplicação da teoria do comportamento planejado. Trabalho de Conclusão de Curso. Curso de Administração. Universidade Federal da Grande Dourados (MS). http://repositorio.ufgd.edu.br/jspui/handle/prefix/2094.

Organização das Nações Unidas.Transformando Nosso Mundo: A Agenda 2030 para o Desenvolvimento Sustentável. 2015. https://nacoesunidas.org/pos2015/agenda2030/.

Peixebr. Anuário da Piscicultura Brasileira - edição 2019. https://www.peixebr.com.br/anuario-peixe-br-da-piscicultura-2019/.

Peixebr. Anuário da Piscicultura Brasileira - edição 2020. https://www.peixebr.com.br/anuario-2020/.

Pereira, G. R.; et al. (2016). Piscicultura continental com enfoque agroecológico. Gaspar: Publicação do IFSC, 2016.

Pereira, Graciane R.; Pires, Henrique da S., Fronteli, Lais. M. (2019). Policultivo de peixes no sistema orgânico. (2019).XI Congresso Brasileiro de Agroecologia. Aracaju, 03 a 07 de Novembro de 2019.

Souza, S. M. G. De; Mathies, V. D.; Fioravanzo, R. F. (2012). Off-flavor por geosmina e 2-Metilisoborneol na aquicultura off-flavor by geosmine and 2-methylisoborneol in aquaculture. Semina: Ciências Agrárias, Londrina, 33(2), 835-846.

Serviço de Proteção ao Consumidor. Hábitos de consumo de pessoas que moram sozinhas. https://www.spcbrasil.org.br/pesquisas/pesquisa/2840.

Santos, G.; Zamberlan, L. (2017). O Perfil do Consumidor de Pescado na Cidade de Santa Rosa - RS. MBA em Marketing. DACEC - Departamento de Ciências Contábeis, Econômicas, Administrativas e da Comunicação. Unijuí - Universidade Regional do Noroeste do Estado do Rio Grande do Sul. 